\title{
Psicólogo na assistência social: o lugar do homem e diálogos epistemológicos feministas na prática profissional
}

\author{
Psychologist in social assistance: the place of man and feminist \\ epistemological dialogues in professional practice
}

\section{Psicólogo en la asistencia social: el lugar del hombre y diálogos epistemológicos feministas en la práctica profesional}

\author{
David Tiago Cardoso ${ }^{\mathrm{a}}$; $^{\text {Adriano Beiras }}{ }^{\mathrm{b}}$ \\ ${ }^{a}$ Psicólogo no Sistema Único de Assistência Social da Prefeitura Municipal de Balneário Camboriú, graduado pela Universidade do \\ Vale do Itajaí (2006), mestre em Psicologia pela Universidade Federal de Santa Catarina (UFSC). Estudante pesquisador no grupo \\ de pesquisa MARGENS. Florianópolis, SC, Brasil-E-mail: cardosodt@gmail.com \\ ${ }^{\text {b }}$ Professor do Programa de Pós-graduação e do Departamento de Psicologia da Universidade Federal de Santa Catarina (UFSC) e \\ coordenador do Curso de Psicologia/UFSC. Doutor Europeu em Psicologia Social (UAB - España), Becas MAEC-AECID. Estágios \\ de Pós-doutorado (UFSC bolsa PDJ - CNPq, Universidad de Granada -UGr-España, University of Brighton-UK). Pesquisador \\ (Margens-UFSC, Brasil, VIPAT-UAB, España), Editor Revista Nova Perspectiva Sistêmica, Florianópolis, SC, Brasil - E-mail: \\ adrianobe@gmail.com
}

Resumo: Traduzir a experiência de corpos cisnormativos masculinos, categorizados como homens, na participação de lugares reconhecidos como femininos, Política Pública de Assistência Social, e feministas, Teorias Feministas Pósestruturalistas, é o objetivo que nos propomos alcançar. Partimos da compreensão de que a experiência, história encenada pela linguagem, produz o sujeito e não algo que o sujeito tenha como propriedade ou que seja anterior a ele. Assim, relatamos nossos percursos nas teorias feministas e a contribuição destas na construção de nossas práticas no Sistema Único de Assistência Social, por meio de três perguntas: Quem somos? De onde viemos? Para onde vamos? Com elas, concluímos que, justamente por sermos homens, precisamos denunciar os privilégios para construir pontes para mudanças e não abismos para a manutenção, rompendo com a generalização da categoria homem, explicitando que estamos em um lugar de homem generificado, produzido pelas normas de gênero, mas que buscamos a desestabilização deste lugar.

Palavras-chave: Teorias feministas. Masculinidades. Política pública de assistência social.

Abstract: This paper aims to translate the experience of cisnormative bodies, categorized as men, into the participation in places recognized as feminine, Social Assistence Policy, and feminists, Post-structuralist Feminist Theories. We understand that experience, history staged by language, produces the subject and it is not something that the subject has as property or a priori. Thus, we report our paths in feminist theories and their contribution in the construction of our practices in the Social Assistance Policy, through three questions: Who are we? Where we came from? Where are we going? With them, we conclude that, because we are men, we need to denounce the privileges to build bridges for change and not abysses for maintenance, breaking with the generalization of the man category, stating that we are in a generalized place of man, produced by the norms of gender, but that we seek the destabilization of this place

Keywords: Feminst theories. Masculinities. Social assistence policy. obra, forneça um link para a licença, e indicar se foram feitas alterações. 
Resumen: La traducción de la experiencia de cuerpos cisnormativos masculinos, categorizados como hombres, en la participación de lugares reconocidos como femeninos, Política Pública de Asistencia Social, y feministas, Teorías Feministas Postestructuralistas, es el objetivo que nos proponemos alcanzar. Partimos de la comprensión de que la experiencia, historia escenificada por el lenguaje, produce al sujeto y no es algo que el sujeto tenga como propiedad o que sea anterior a él. Así, relatamos nuestros recorridos en las teorías feministas y la contribución de éstas en la construcción de nuestras prácticas en el Sistema Único de Asistencia Social, por medio de tres preguntas: ¿Quienes somos? ¿De dónde venimos? ¿Para donde vamos? Con ellas, concluimos que, justamente por ser hombres, necesitamos denunciar los privilegios para construir puentes para cambios y no abismos para el mantenimiento, rompiendo con la generalización de la categoría hombre, explicitando que estamos en un lugar de hombre generalizado, producido por las normas de género pero que buscamos la desestabilización de este lugar.

Palabras clave: Teorías feministas. Masculinidades. Política pública de asistencia social.

\section{Como citar o artigo:}

CARDOSO, T. D; BEIRAS, A. Psicólogo na assistência social: o lugar do homem e diálogos epistemológicos feministas na prática profissional. Revista de Ciências Humanas, Florianópolis, v.52, 2018. DOI: 10.5007/21784582.2018.56983

\section{INTRODUÇÃO}

Encontrar palavras que traduzam a experiência de estudar as Teorias Feministas e fundamentar nossas práticas profissionais no Sistema Único de Assistência Social enquanto homens é a centralidade desse artigo, buscando, por meios destas teorias, aventurar-nos pelas seguintes questões: Quem somos? De onde viemos? Para onde vamos? Estas questões geram instabilidades e afetamentos que surgem no horizonte como inquietações, de uma experiência geradora de desconforto frente aos estudos realizados destas Teorias, em especial as teorias e argumentações de Butler (1998, 2003, 2015), Haraway (1995), Harding (1998), Nogueira (2001, 2013), Scott (1998) e Preciado (2011), para citar algumas. Estas teorias e argumentações produzem críticas unânimes frente ao enviesamento androcêntrico nas práticas científicas e na produção de conhecimentos que desconsideram o sexo/gênero feminino e a experiência feminina, identificando a masculinidade como universal, generalizando por meio desta, os saberes (NOGUEIRA, 2017)

Partimos da compreensão de que a experiência produz o sujeito e não algo que o sujeito tenha como propriedade ou que seja anterior a este sujeito, neste sentido, a experiência é a história encenada por meio da linguagem, na qualidade produtiva do discurso e por meio dela os sujeitos podem se tornar visíveis (SCOTT, 1998). Assim, a experiência do nosso desconforto não se dá apenas pelo estudo das referidas teorias, mas também em aplica-las nos espaços em que atuação profissional se faz necessária, aqui, o Sistema Único de Assistência Social (SUAS).

Ressaltamos, portanto, que nosso desconforto não pretende produzir reatividade e nem é produto dela, ou seja, uma defesa de nossas masculinidades e de manutenção do status quo, queremos sim colocar o desconforto como a potência de produção de novos sentidos, reflexivos e potencializadores, que possam desestabilizar categorias, desconstruir práticas, democratizá-las, para então reconstruir de modo igualitário e horizontalizando as relações sociais. Falar da nossa 
experiência, torná-la visível, é uma estratégia que pretendemos utilizar para encontrar ecos em outras experiências, de modo a criar um coletivo de corpos que se permitam utilizar as teorias feministas em seus cotidianos de trabalho.

Nossa experiência começa a ser construída a partir de encontros e desencontros epistemológicos que estas teorias trazem na possibilidade de fundamentar o trabalho social com famílias e pesquisas que tem como interesse a Assistência Social, e dos encontros que foram sendo construídos em conjunto com feministas teóricas e feministas militantes, cisgêneras, transgêneras, não-binárias, heterossexuais, homossexuais e bissexuais.

Da tensão destes encontros, questões começaram a surgir e que podemos definir aqui como um primeiro desconforto: Pode um homem utilizar as teorias feministas em seu cotidiano profissional? Existe um lugar para os homens como produtores de conhecimento nestas teorias? Homens feministas, pró-feministas ou apenas feministas? Destes questionamentos, organizamos nossos desconfortos em dois: Primeiro o desconforto em ser homem e o segundo, um desconforto com relação à prática profissional.

Estes desconfortos encontram lugar quando, a partir das apropriações das teorias feministas, buscamos uma tradução para o cotidiano profissional, como psicólogos homens que atuam no SUAS, no trabalho social com as famílias vulnerabilizadas e através do projeto de pesquisa intitulado "Homens, violências, subjetividades - intervenção e pesquisa político-feminista", ambos tendo como campo de intervenção os Centros de Referência de Assistência Social (CRAS) e os Centros de Referência Especializado de Assistência Social (CREAS).

Destacamos que este projeto de pesquisa teve como objetivo mapear as necessidades locais na região da Grande Florianópolis, Santa Catarina, no que se refere à atenção ao tema da violência contra mulheres e ao trabalho com autores de violência, em serviços locais de assistência social e segurança pública, tendo como sujeitos os profissionais da Psicologia. O estudo foi realizado por meio de entrevistas qualitativas com estes profissionais, sendo o conteúdo analisado a partir da análise temática de narrativas. Já o trabalho social com famílias tem lugar no município de Balneário Camboriú, também em Santa Catarina, acontecendo em espaços distintos, primeiramente em CREAS, após em um CRAS e, mais recente, na Secretaria que organiza o SUAS neste município.

Compreendemos o SUAS por aquilo que o fundamenta, seus princípios: supremacia do atendimento às necessidades sociais, universalização dos direitos sociais, respeito à dignidade do cidadão, à sua autonomia e ao seu direito a benefícios e serviços de qualidade, bem como à convivência familiar e comunitária (BRASIL, 1993). Esses princípios o tornam um campo de intervenção do saber psicológico, e como tal, precisa ser problematizado. 
Por ora, parece-nos que, se de certa forma as Teorias Feministas realizam embates que buscam justamente a universalização dos direitos, respeito à dignidade e à autonomia das mulheres, de lésbicas, gays, bissexuais, transgêneros, esse desconforto pode se tornar uma falácia. Contudo, como transformar categorias como interseccionalidade e masculinidades, para citar algumas, em ferramentas que possibilitem a transformação da realidade social dos sujeitos atendidos pelos profissionais do SUAS? Aqui está a fonte do segundo desconforto revelada.

Tendo dado visibilidade aos desconfortos de nossa experiência, buscaremos compreendê-los por meio das instabilidades e afetamentos, respondendo as perguntas apresentadas: Quem somos? De onde viemos? Para onde vamos? Acreditamos que essas perguntas podem servir como um norte, apontando onde queremos chegar.

\section{QUEM SOMOS?}

Ao nos depararmos neste presente fluído, que ao final deste artigo já será passado, encontraremos uma primeira categoria, que nos definirá como espécie. Ser humano. Humano em forma genética e, portanto, biológica, sendo assim, não temos dúvidas desta humanidade. Contudo, essa certeza começa a ser questionada quando compreendemos que estamos dentro de uma matriz de inteligibilidade, enquadrados como vidas, que encontraram condições de se tornar uma vida possível de ser vivida (BUTLER, 2015).

Assumir que somos vidas, e que esta vida é "vivível" nos coloca frente a dilemas: A Assistência Social, enquanto política pública, se propõe a atender quem dela necessitar, então qual o enquadramento que utilizamos para definir quem necessita dela? Em outras palavras, quais vidas são vidas possíveis de atendimento no SUAS?

O que queremos destacar é que nem tudo que está vivo é considerado vida, ou seja, para que o vivo seja considerado vida, deve ser produzido de acordo com as normas pelas quais a vida é reconhecível (BUTLER, 2015). De certo modo, é colocar pontos de interrogação nos que vivem nos territórios atendidos pela Assistência Social, se podem ser enquadrados enquanto vida: Traficantes? Prostitutas? Adolescentes em conflito com a lei? Travestis?

Podemos ir além: Se estes desaparecessem dos territórios teriam sua ausência notada pelas trabalhadoras e trabalhadores da Assistência Social? Se morressem, seriam vidas passíveis de luto, seriam vidas choráveis? Não nos parece sincera uma resposta afirmativa, pois apenas em condições em que a perda tem importância é que o valor da vida aparece de modo efetivo (BUTLER, 2015). Quando os vivos acima dificilmente chegam aos CRAS e CREAS, quando chegam, o que precisamos discutir é se estão enquadrados como vidas que merecem atendimento das equipes técnicas 
(psicólogos, assistentes sociais, pedagogos, para citar alguns). Deixamos como provocação uma citação da Butler (2015, p. 43) "onde uma vida não tem nenhuma chance de florescer é onde devemos nos esforçar para melhorar as condições de vida".

É preciso dizer que paira no ar dúvidas da escolha dessa primeira categoria, pelo simples fato de tentar fugir conscientemente da categoria "homem”, todavia é inevitável. É inevitável, porque não se nasce humano em nossa cultura, se nasce "menino" ou "menina", não há muitos meios para escapar. Deste modo, "nascemos" meninos e fomos criados como tal. Essas aspas que surgem levam a problematizar esse homem, esse menino, essa menina que nascem.

Nascer homem ou mulher é nascer com o aparato sexual masculino e feminino. Ou seja, quando falo de homem e menino, estou falando de sexo e também de gênero. Em outras palavras, quando escolhem dizer "é um menino", escolhem por aquele feto tem o aparato sexual masculino, aparato que recebe essa determinação de "masculino" por meio de um discurso biomédico. Apresentase, então, um emaranhado conceitual que precisa ser resolvido.

Butler (2003) questiona esse sexo biológico e, portanto, imutável, trazendo à discussão Michel Foucault, quando na sua compreensão o corpo não é biologicamente sexuado em nenhum sentido significativo antes de sua determinação num discurso pelo qual ele é investido de uma ideia de sexo natural, assim, a sexualidade irá produzir este sexo como um conceito artificial. Butler (2003) resgata Monique Witting, que advoga nesse sentido, pois a mesma considera que o 'sexo' é discursivamente produzido e difundido por um sistema de significações opressivo para as mulheres, aos gays e às lésbicas. Em outras palavras, o sexo deixa de ser entendido como algo dado em essencial pela natureza, ele é produzido pelo discurso e tem uma intencionalidade, a opressão.

Nesse processo de desnaturalização, também está o "gênero". Butler (2003) aborda que o feminismo humanista compreendia o gênero como um atributo da pessoa, ou seja, o gênero seria substancial e, portanto, preestabelecido. Essa visão essencialista apresentada é desconstruída pela autora, ao afirmar que como fenômeno inconstante e contextual, o gênero não denota um ser substantivo, mas um ponto relativo de convergência entre conjuntos específicos de relações, cultural e historicamente convergentes (BUTLER, 2003). O gênero denota relações, construções e desconstruções, estando sempre instável.

Nogueira (2001) compartilha desse argumento da não-substância, afirmando que

o gênero não é uma questão de identidades individuais, unitárias e consistentes de homem e mulher, pelo contrário desenvolve-se mediante peças de discurso, organizadas num sistema de significados disponíveis aos indivíduos de forma a darem sentido às suas posições, o que historicamente é reconhecido como respostas femininas e masculinas. (p. 147)

Para Preciado (2011, p. 14) “O gênero não é o efeito de um sistema fechado de poder nem uma ideia que recai sobre a matéria passiva, mas o nome do conjunto de dispositivos sexopolíticos 
(da medicina à representação pornográfica, passando pelas instituições familiares)". Gênero, portanto, não é ser, mas sim um fluído é sendo, não é algo original e a priori no mundo, é construído pelo discurso.

Contudo, esse gênero não se faz solitário, se faz de modo interseccional, pois está atravessado pela "raça", classe social, nacionalidade e tantas outras categorias que vão nos constituindo como sujeitos (NOGUEIRA, 2013). Portanto, não basta dizer que somos homens, afinal, precisamos também deflagrar a branquitude, não tão branca assim, dizer que estamos na classe média, e ainda, nascidos brasileiros e possuindo ensino superior, apenas para citar algumas dessas categorias que vão garantindo privilégios.

Cabe ressaltar que essas categorias se relacionam de modo a transcender uma identidade de somatória, acumulativa (homem+branco+classe média...), pois essa identidade é multiplicativa (homem x branco x classe média...). Nogueira (2013, p. 232) afirma que "todas as facetas da identidade são partes integrais inter-relacionadas de um todo complexo, sinérgico e infundido que torna tudo completamente diferente quando as partes são ignoradas, esquecidas ou não mencionadas". É preciso mencionar que a interseccionalidade resiste à essencialização dessas categorias, tal como sexo e gênero, também não estão aprioristicamente no mundo, são construídas discursivamente, e precisa-se estar atento às especificidades da data, do local, das histórias e das localizações (NOGUEIRA, 2013).

Os efeitos dessa interseccionalidade sobre a atuação junto as famílias e com as/os profissionais permitem-nos refletir: Como estas normas ou até expectativas de gênero interferem em nossas atuações e percepção da realidade do trabalho? Como ela produz determinados entendimentos limitados e invisibiliza diversidades?

As famílias que acessam os Centros de Referência de Assistência Social não chegam enquanto família, quem acessa os serviços são mulheres, em sua maioria se referenciando como "donas de casa", identificadas nos prontuários como "referência da família". São mulheres, negras ou pardas, com ensino fundamental incompleto, vulnerabilizadas pela condição financeira, enquadras dentro da categoria pobres ou em extrema pobreza.

O que parece ser um simples atendimento de demandas sociais pode se revelar um reforço das normas marcadas pelo gênero, onde o profissional que atende, detentor do saber científico e, portanto, da verdade, determina o que a mulher (em atendimento) deve fazer para que sua realidade seja transformada. Essa norma que coloca a mulher como cuidadora, na Assistência Social pode ser ainda mais perversa, pois ao colocá-la como responsável pela família também a coloca em um lugar de responsável pelas dificuldades que toda a família vivencia, podendo cair em narrativas como: "não fiz nada para meu filho não ser abusado"; "Sou incapaz de superar essas dificuldades sozinha, preciso 
de ajuda de um homem, e se meu marido for embora, como vou fazer para viver?". Em outras palavras, a expectativa sobre o gênero é reforçada pelo foco na mulher como cuidadora e a ausência do homem aos atendimentos pela justificativa que não pode por estar trabalhando.

Os parágrafos acima denunciam a invisibilidade de toda uma população quando focamos na relação binária mulher-homem enquanto família que acessa os serviços socioassistenciais. Mas se a Assistência Social pretende ser a porta de entrada, precisa alargar as dimensões dessa porta para poder contribuir na visibilidade a estes outros sujeitos: a população trans, por exemplo.

O que acontece para a população trans não acessar os serviços do SUAS? Estaria fora da matriz de inteligibilidade? A experiência profissional do primeiro autor deste artigo, atuando na Assistência Social há seis anos, revela um único atendimento a uma mulher trans, esta em situação de rua e não encontrando acolhida em qualquer serviço. Quando foi ao CRAS não foi atendida pela equipe com a justificativa de não ser do residente do território, quando chegou ao CREAS a justificativa encontrada foi a de que não vivenciava violência, chegando então a Secretaria de Assistência Social do município, onde atualmente o autor exerce seu trabalho.

A demanda desta mulher era sair da rua, encontrar um lugar para ficar até conseguir pagar o primeiro aluguel de um quarto. Contudo, essa demanda fácil de ser resolvida, pois o município possui um serviço de acolhimento institucional na modalidade casa de passagem, demonstrou-se ainda mais complexa, estando os quartos separados por "sexo", masculinos de um lado, femininos de outro, a coordenação realiza a separação dos corpos pela documentação civil, em outras palavras, a mulher trans teria que dormir junto com os homens, o que para ela se revelava uma real possibilidade de ser violentada sexualmente. Em resumo, após muitos enfrentamentos, a coordenação autorizou que ela ficasse no dormitório feminino, apenas porque não havia nenhuma outra mulher acolhida.

Essa experiência foi muito além de revelar a ineficiência dos serviços socioassistenciais em atender as demandas dessa população. Revelou também que, até então, o primeiro autor nunca havia pensado em como atender essa população, quais as demandas específicas e como elas precisam ser acolhidas, ou seja, a população trans naquele momento não estava enquadrada como público da Assistência Social. Ainda, surgiu outra questão: se um homem pode "performar" como mulher, se fazer mulher, se desfazendo de todo um modo de ser homem, seria o modo de ser homem construído?

Esse "modo de ser homem" é transformado aqui na categoria "masculinidade", de modo a problematizar e buscar torná-la uma categoria útil para a Assistência Social. Desta forma, Connell e Messerschmidt (2013) partem da compreensão que a masculinidade não é uma entidade fixa que o corpo encarna ou que está presente nos traços da personalidade dos indivíduos, sendo então configurações práticas realizadas na ação social, assim, podem se diferenciar de acordo com as relações de gênero de um determinado cenário social particular. 
Se a masculinidade não é fixa, podendo ser diferente nas diversas culturas e nos diversos tempos históricos, embora mantenha uma aparência natural e ahistórica, podemos afirmar então que a masculinidade é uma categoria vazia, preenchida por discursos atravessados por estas culturas e pelas relações sociais e de poder (BUTLER, 2003). Assim, a masculinidade é a própria performatividade de corpos generificados que pretendem se enquadrar como "homem", fugindo ao aspecto essencialista, pois não atribui aos corpos e à personalidade algo estático e imutável, podendo ser posta em atos por pessoas em corpos femininos (NÚÑEZ NORIEGA, 2008). O "homem" que somos é aquilo que performamos enquanto masculinidade e aquilo que esperam de nós enquanto performatividade, ou seja, uma ficção cultural que deve ser encenada pelos nossos corpos e pela linguagem em ação. Nessas linhas fica evidente que a essencialidade, esse sou, deixa de existir. O desconforto, em resumo, é a própria impossibilidade de não poder mais dizer que somos, mas que estamos e que daqui a pouco podemos estar sendo outro. Ao afirmar que não nascemos com categorias substanciais, mas estas categorias são atribuídas pelo discurso de uma determinada cultura, como uma norma que devemos seguir, podemos pensar na Assistência Social como um lugar para trabalhar as masculinidades, buscando construir em conjunto com os sujeitos um modo de ser masculino fundamentado na igualdade, sem hierarquizar as relações sociais.

Como um modelo potencialmente possível (FLOOD, 2011) para o SUAS queremos trazer a experiência da entidade não governamental conhecida como Instituto PAPAI, com sede no Recife, Pernambuco, que trabalha fundamentado nos princípios feministas e na defesa de uma sociedade mais justa, onde homens e mulheres tenham os mesmos direitos, por meio da promoção do envolvimento dos homens, a cessação dos sentidos de ser homem, de masculinidades nos processos de socialização na sociedade de hoje e do impacto sobre as políticas públicas (BEIRAS; NUERNBERG; ADRIÃO, 2012; MORENO, 2016).

Outra prática potencialmente possível, para situar em termos locais, é realizada no município de Blumenau, que iniciou como um programa de atendimento no início da década de 2000, coordenado pelo assistente social Ricardo Bortoli, e atualmente é realizada como estratégia da política pública de Assistência Social. As intervenções acontecem em dois eixos, o da Proteção, por meio do serviço de abrigamento às mulheres e seus filhos em situação de risco pessoal provocado pelo fenômeno da violência doméstica, e o eixo da Prevenção e Promoção, com os homens destas famílias em situação de violência doméstica (BEIRAS, 2014).

Existem outras práticas que poderiam ser citadas (BEIRAS, 2013; TONELI; et al., 2010), contudo as duas práticas foram escolhidas por serem experiências em âmbito nacional que se fundamentam nas teorias feministas para a compreensão das masculinidades. Da mesma forma, foram escolhidas por provocarem as políticas públicas a pensar estratégias que deem visibilidade aos 
homens enquanto sujeitos possíveis, e em nossa compreensão, necessários, de intervenção e não mais como sujeitos genéricos (NÚÑEZ NORIEGA, 2008) e, portanto, excluídos do interesse científico e das práticas profissionais.

\section{DE ONDE VIEMOS?}

Seguimos na reflexão sobre a prática profissional por meio das teorias feministas. Nesta necessária tradução daquilo que está escrito em ações que, por vezes, serão transcritas, produzindo novas escrituras. Fato é, que atravessa em nossas consciências, a todo momento, o desconforto de existir em um corpo masculino que nos joga, nos faz escorregar e nos faz cair em privilégios em um campo de atuação construído por mulheres, o Sistema Único de Assistência Social - SUAS, lugar de onde viemos e voltamos diariamente enquanto trabalhadores e pesquisadores.

O SUAS é quem organiza e executa a política de proteção social, concebida pela Constituição Federal Brasileira, de 1988. Constitui, ao menos em suas Orientações Técnicas (BRASIL, 2009, 2011, 2012), o trabalho social para a superação de barreiras, vulnerabilidades, riscos e violação de direitos sociais produzidas pela história sociopolítica brasileira. É na Política Nacional de Assistência Social (PNAS), que a política de proteção social será explanada e dividida em suas duas proteções: Proteção Social Básica e Proteção Social Especial.

A Proteção Social Básica tem como objetivos prevenir situações de risco por meio do desenvolvimento de potencialidades e aquisições materiais, bem como o fortalecimento de vínculos familiares e comunitários (BRASIL, 2004), tendo como espaço dialógico e democrático representado pelo Centro de Referência de Assistência Social (CRAS), que “[...] pela oferta de serviços, benefícios e atividades socioassistenciais, materializa direitos a proteção social de assistência social, como dever de Estado" (YAZBEK et al., 2014, p. 151). É, portanto, dever do Estado desenvolver estratégias que permitam desenvolver as potencialidades e aquisições dos sujeitos, e que, em coletividade, possam construir meios de prevenir situações de risco social que fragilizam os vínculos.

Quando estas estratégias não conseguem exercer sua função de proteção no fortalecimento de vínculos de convivência familiar e comunitária, a proteção social básica abre espaço para a atuação do SUAS em um outro nível de atendimento, focando suas ações caracterizadas como especializadas. Desta forma, a Proteção Social Especial, “[...] é a modalidade de atendimento assistencial destinada a famílias e indivíduos que se encontram em situação de risco pessoal e social, por violação de direitos [...]” (BRASIL, 2004, p. 37), utilizando de mediações como estratégia de superação das situações de violações de direitos e do rompimento dos ciclos de violências que acontecem no cotidiano da família. A atuação colocando a família enquanto centralidade, permite desconstruir as situações de violações 
de direito como algo natural, dado e acabado, mas em um fluxo contínuo de transformações e possibilidades.

A atuação como psicólogo do SUAS constitui-se, portanto, de entrar em contato com as famílias em situação de pobreza e extrema pobreza e suas histórias, e com elas, pensar um projeto de empoderamento que vise, além das aquisições materiais (recursos financeiros, alimentos, moradia, para citar alguns), a autonomia e emancipação que superem as violações de direitos que vivenciam. Entretanto, surge o questionamento: como a Psicologia se propõe a responder essas demandas sociais?

$\mathrm{Na}$ última década, percebe-se que a ciência Psicologia buscou compreender cada vez mais a profissão Psicologia nesta inserção na Assistência Social, por ser um campo de atuação novo, desta forma, queremos destacar alguns estudos que merecem atenção. Ximenes, Paula e Barros (2009) se interessam sobre os diálogos possíveis da atuação da/o psicóloga/a em comunidades, buscando a compreensão dos aportes teóricos-metodológicos dos profissionais, as correlações que perpassam a atuação e as implicações da prática nos microespaços, concluindo que a práxis pode tanto atualizar ordens socialmente excludentes quanto a produção de fissuras nas iniquidades sociais.

Andrade e Romagnoli (2010) realizam uma cartografia do psicólogo no CRAS, colocando a Psicologia em um lugar que se apresenta como um espaço fluido, em permanente transformações, definindo este lugar como um espaço de encontros e acontecimentos singulares, ressaltando que os profissionais devem insistir em não se adaptarem as exigências do mundo e em inventar, mas sim se conectar com territórios que escapam a psicopatologização da vida.

No estudo realizado por Santos (2015), que tem o interesse na atuação com compromisso social, detecta problemas similares aos estudos acima citados, onde as profissionais naturalizam a desigualdade social, o que indica a necessidade de se pensar novas leituras sobre os problemas sociais vivenciados pelos usuários, possibilitando o enfrentamento desses.

Mais recente, Romagnoli (2016) buscou compreender as relações macropolíticas e micropolíticas no cotidiano do CRAS, trazendo que embora o modelo do SUAS ser democrático e fecundo no papel, a autora problematiza que são as/os profissionais que viabilizam ou não, estando atravessados pelo que compreendem da política de assistência social, a demanda de trabalho, a dificuldade de promover a intersetorialidade, a relação que possuem com o território de atuação e a importância do trabalho coletivo.

Embora utilizamos autores da Psicologia para falar de como esta ciência busca compreender o trabalho da/o psicóloga/o na Assistência Social, o fato é que os documentos produzidos para orientar a prática nesta política social possuem, em sua maioria, referencial teórico do Serviço Social. Basta analisar as referências bibliográficas, em especial dos documentos: "Orientações Técnicas: Centro de Referência Especializado de Assistência Social - CREAS" (BRASIL, 2011), "Orientações Técnicas 
sobre o PAIF - Volume 2" (BRASIL, 2012) e o mais recente "Fundamentos ético-políticos e rumos teórico-metodológicos para fortalecer o Trabalho Social com Famílias na Política Nacional de Assistência Social" (BRASIL, 2016).

Essa denúncia não pretende invalidar o saber do Serviço Social e suas importantes contribuições para a efetivação da Assistência Social enquanto política pública, muito menos vitimizar a Psicologia, a colocando em um lugar marginal desta política. A intenção é demonstrar a fragilidade do campo de atuação, onde profissionais da Psicologia precisam "inventar" (ANDRADE; ROMAGNOLI, 2010) o trabalho com as famílias atendidas e acompanhadas, haja vista que as orientações técnicas não contemplam a especificidade do saber psicológico.

De modo a minimizar essa inventividade o Centro de Referências Técnicas em Psicologia e Políticas Públicas (CREPOP), vinculado ao Conselho Federal de Psicologia, produziu referências técnicas específicas àquelas profissionais que atuam no SUAS: "Referências Técnicas para atuação do(a) Psicólogo(a) no CRAS/SUAS" (CONSELHO FEDERAL DE PSICOLOGIA, 2007), "Referência Técnica para Atuação de Psicólogas(os) em Programas de Medidas Socioeducativas em Meio Aberto" (CONSELHO FEDERAL DE PSICOLOGIA, 2012) e "Referências Técnicas sobre a Prática de Psicólogas (os) no Centro de Referência Especializado da Assistência Social - CREAS" (CONSELHO FEDERAL DE PSICOLOGIA, 2013). Contudo, nesses documentos pouco, ou nada, é abordado sobre Gênero enquanto categoria a ser trabalhada junto as famílias.

Dos três documentos, apenas o relativo ao CREAS cita gênero, ainda como uma possiblidade de fragilização dos vínculos afetivos e que permite a vivência de vulnerabilidade social, fazendo uma citação da Política Nacional de Assistência Social, isso porque, dos sujeitos público alvo inclui-se as mulheres, excluindo homens e toda a população LGBT.

Embora esses documentos não tragam explicitamente gênero como categoria para o trabalho, eles dão direções, sendo uma delas o trabalho coletivos com as famílias, como aborda a referência técnica do CREAS, afirmando que é importante sair do "[...] lugar de identificação de 'problemas', de culpabilização ou busca de responsáveis, para o lugar de viabilizadores de espaços criativos e geradores de alternativas individuais e coletivas na perspectiva da superação das situações de violação" (CREPOP, 2013, p. 60). Desta forma, a Psicologia, enquanto profissão, pretende superar a inventividade e dar espaço a criatividade, pensando em coletividades sem deixar de estar atento as demandas individuais. Mas a Psicologia enquanto ciência o que pretende?

Nossa prática acadêmica constrói o SUAS como um campo de pesquisa possível por meio do projeto "Homens, Subjetividades e Violências" que engloba atuações psicoeducativas e sociocomunitárias em uma atuação voltada às políticas públicas e aos diálogos interdisciplinares, tendo como das perguntas norteadoras: " Quais as iniciativas existentes no Brasil 
contemporaneamente de atenção grupal ou individual para homens autores de violência contra mulheres? Como estas iniciativas têm inserido o feminismo e os estudos de masculinidades como ferramentas teóricas? Que dificuldades existem e o que necessita ser aprimorado? Que tipo de atenção tem sido dado aos autores de violência no âmbito dos CRAS e CREAS ", traduzindo como objetivo estimular estudos sobre o tema da intervenção com autores de violência e mulheres maltratadas, a partir de uma perspectiva político-feminista, de diversidade e direitos humanos, entre alunos e alunas de graduação e pós-graduação.

Para tal, os pesquisadores se inserem no campo e constroem uma relação que possibilite, por meio de entrevistas e das narrativas dos profissionais entrevistados pensar como a atuação vem sendo realizada, se são práticas fundamentadas em teorias, quais são elas, se há uma compreensão das teorias feministas e suas categorias de análise, ou se estes profissionais partem de lugar de senso comum ou bom senso justificadas pelas demandas do cotidiano de trabalho.

Evidenciamos que na prática profissional no SUAS pelo primeiro autor, a Psicologia Social Crítica vem dando bases para a atuação, enquanto na prática acadêmica do segundo autor a fundamentação está embasada nas teorias feministas pós-estruturalistas, o que não demanda problema algum, pois algumas análises vêm apontando similaridades entre esta Psicologia e a trajetória feminista (BORGES, 2014). Contudo surge uma inquietação: Como transformar os fundamentos epistemológicos feministas em ferramenta de trabalho no trabalho social no SUAS?

Essa questão surge no desvelar de tensões em trabalhar com sujeitos, em sua maioria mulheres, a respeito de Relações de Gênero e Interseccionalidade, usando as teorias feministas para instrumentalizar o trabalho, sendo homens. Estaríamos nos apropriando do discurso feminista para manter esse privilégio de fala, que autoriza ou desautoriza essas mulheres a falar de suas experiências?

Chagoya (2014) nos ajuda ao trazer a luz da discussão uma tendência discursiva que posiciona os homens frente ao feminismo denominada "profeminista e/ou antissexista". Esta tendência vem crescendo, aspirando converter-se em movimento social, sendo formada por homens de classe média, com formação nas áreas de Ciências Sociais ou Humanidades, que buscam desconstruir a masculinidade tradicional.

Salientamos que Chagoya (2014) trata desta tendência no México, contudo podemos observar que, embora timidamente, esta tendência também vem ampliando e encontrando seu espaço no Brasil. Neste sentido, para dar conta do nosso desconforto, encontramos nessa tendência um lugar de fala que nos permite falar em conjunto com as feministas tanto no âmbito acadêmico quanto na prática profissional e por isso nos permitimos questionar: Para onde vamos, afinal? 


\section{PARA ONDE VAMOS?}

A questão talvez não seja propriamente "para onde vamos?", mas "para onde estamos indo?", pois não estamos parados em uma encruzilhada epistemológica, como buscamos deixar bem definido ao longo do artigo. Ressaltamos que as teorias feministas já estão fundamentando nossas práticas e abrindo caminhos para novos sentidos de pesquisa. De que forma?

Beiras, Benvenutti e Toneli (2016) concluem que a utilização das teorias feministas, em especial a Teoria Feminista Pós-estruturalista, pode promover um olhar para a diversidade, transcendendo dicotomias, reducionismos, essencializações e naturalizações. Para tal, Haraway (1995, p. 30) contribui ao trazer à luz da discussão a objetividade feminista, sendo esta a produção de saberes localizados, ou seja, a defesa é "[...] a favor de políticas e epistemologias de alocação, posicionamento e situação nas quais parcialidade e não universalidade é a condição de ser ouvido nas propostas a fazer de conhecimento racional".

Esses posicionamentos, feministas e de interseccionalidade, estão possibilitando uma autorreflexão diária de nossas práticas no campo, permitindo compreender que os sujeitos de pesquisa e os sujeitos de intervenção produzem sentidos e conhecimentos sobre suas vidas naqueles espaços e contextos que vivenciam e que esses sentidos e conhecimentos acontecem ali e não necessariamente podem ser utilizados para explicar os sentidos e conhecimentos de outros sujeitos em outros espaços.

Além disso, a Psicologia que pretende ser crítica, precisa questionar sua produção de conhecimento e de práticas de trabalho, colocando em questão quais interesses ela legitima e quem é o destinatário dessa produção, situar o discurso cientifico como uma possibilidade discursiva que produz efeitos no modo de vida e não como um modo privilegiado de ter acesso à verdade (MOSCHETA, 2014). Esse reconhecimento do caráter político do fazer científico permite questionar pressupostos normativos e desestabilizar discursos sociais essencialistas e universalizantes (BORGES, 2014).

Queremos afirmar com isso que nossa prática a todo momento está sendo questionada por nós, para não criarmos verdades absolutas sobre os sujeitos com os quais atuamos em nosso cotidiano de trabalho. Não queremos criar uma explicação universal que serve a todos os sujeitos, nossa intenção é possibilitar a produção de sentidos que rompa com as relações de poder opressoras e verticalizadas.

Para tal, deixamos vivas as palavras de Harding (1998, p. 24) que compreende que "La investigación social tradicional ha estado a favor de los hombres. En los mejores estudios feministas, los propósitos de la investigación y del análises son inseparables de los origenes de los problemas de investigación". Desta forma, as teorias feministas dão a possibilidade de repensar caminhos e de construir novos caminhos às ciências, de modo a alterar o status quo e de privilégios dos homens. 
Haraway (1995, p. 35) defende que "O feminismo tem a ver com uma visão crítica, consequente com um posicionamento crítico num espaço social não homogêneo e marcado pelo gênero". Este olhar feminista ajuda-nos a ter mais cuidados na sala de aula, nos grupos de usuárias ou de trabalhadoras e trabalhadores, olhando e interpretando a realidade com o gênero e feminismos como operadores analíticos, tensionando posições e reflexões e estando em constante reconstrução e vigilância desta atuação.

Contudo, algo sempre escapa, pois, o discurso nos construiu como homens em uma sociedade machista, o que não quer dizer que estamos nos desculpando ou criando desculpas, mas sim, apontar que estamos abertos aos apontamentos e para tal é necessário construir uma relação em que o outro pode apontar o que escapou de modo colaborativo e não reativo, ou seja, uma relação em que o diálogo seja para construir e não para (re)marcar lugares de opressor e oprimido. Em um aspecto teórico, Butler (1998, p. 22) argumenta, complementando, que "uma teoria social comprometida com a disputa democrática dentro de um horizonte pós-colonial precisa encontrar uma maneira de pôr em questão os fundamentos que é obrigada a estabelecer".

Assim, se é impossível desconectar teoria e prática, a compreensão e as mudanças que as teorias feministas realizam, a impossibilidade de traduzi-las em práticas de trabalho inexiste, pois "[...] a capacidade de agir pertence a um modo de pensar sobre as pessoas como atores instrumentais que confrontam um campo político externo". (BUTLER, 1998, p. 30-31). Isso significa dizer que a prática no trabalho social produz realidades dentro de uma arena de disputas e tensões, e se esta prática estiver imersa e mediada pelas teorias feministas, realidades e práticas menos opressoras poderão ser produzidas.

Queremos reafirmar nesses termos que as teorias feministas podem ser utilizados como ferramentas teóricas e epistemológicas. Como exemplo, podemos citar o trabalho realizado por meio de um desmembramento do projeto de pesquisa já citado, Homens, violências, subjetividades intervenção e pesquisa político-feminista, que teve como objetivo mapear as necessidades locais na região da Grande Florianópolis, Santa Catarina, no que se refere à atenção ao tema da violência contra mulheres e ao trabalho com autores de violência, em serviços locais de assistência social e segurança pública, com profissionais da Psicologia.

O estudo foi realizado por meio de entrevistas qualitativas com estes profissionais, sendo o conteúdo analisado a partir da análise temática de narrativas. Dessa inserção, foi possível verificar a dificuldade de diálogo entre o "mundo" da academia e prática profissional no SUAS, deste distanciamento, o que se percebe é que a referida prática acontece sem a fundamentação de uma teoria necessariamente, seja ela crítica ou não, o que pode estar gerando um lugar de bom senso, ou seja, o uso dos profissional como sujeito de referência para a transformação que o outro precisa ter. Uma 
prática, por vezes posicionada nos próprios limites e "pré-conceitos" de gênero, fundada nas limitações de um lugar não crítico de raça, classe e outras interseccionalidades. Assim, foi possível apontar a necessidade capacitações específicas, reflexões críticas da prática, discussões teóricoepistemológicas relacionadas ao trabalho com autores de violência e sobre aspectos teóricos de gênero, feminismos, promoção de diferentes masculinidades e subjetividades, distanciadas de violências.

\section{CONSIDERAÇÕES FINAIS}

É importante destacar que o estudo acadêmico-teórico e do movimento feminista no âmbito da Psicologia tem cada vez mais recebido propostas de pesquisas e intervenções, contudo também é necessário destacar que essa ampliação não está isenta de resistências e confusões. Essas tensões também se traduzem no ambiente profissional, contudo entendemos que as teorias feministas contribuem com uma psicologia crítica que considera aspectos políticos e de direitos humanos, e que busque estratégias que promovam transformação social e busca pela igualdade de direitos (BEIRAS; BEVENUTTI; TONELI, 2016).

A proposta é justamente o desafio proposto por Gergen e Gergen (2010, p. 31), “[...] não é encontrar a 'única e melhor forma', mas criar tipos de relação através dos quais se possa construir o futuro de maneira colaborativa". Para que esta condição de homem (heterossexual x branco x de classe média...), com todos seus privilégios, permaneça desconfortável talvez seja necessário que as Teorias Feministas continuem a gerar o desconforto nestas categorias, isso para que as profundas mudanças sociais que precisam acontecer, aconteçam de maneira colaborativa.

Em outras palavras, é preciso denunciar esses privilégios de modo a construir pontes para mudanças e não abismos para a manutenção, rompendo com a generalização da categoria homem (NÚÑEZ NORIEGA, 2008), deixando explicito que estamos falando de um lugar de homem que também é generificado, produzido pelas normas de gênero, mas que se busca desestabilizar esse lugar.

Como exemplo, podemos citar duas situações: A primeira delas faz parte da experiência apenas do primeiro autor, que ao ser convidado para ser palestrante na Conferência Municipal de Assistência Social do município de Balneário Camboriú, questiona o porquê de sido o escolhido, se em uma política pública em que a maioria é mulher, porque um homem é quem deveria fazer a fala? Por que um homem branco da classe média teria o poder de falar para os sujeitos que fazem parte da assistência social e sabidamente são mulheres?

A outra experiência envolve ambos os autores deste artigo e aconteceu no âmbito acadêmico, em sala de aula. Na avaliação discente, os alunos colocaram que existia um recorte de gênero no 
modo como tratávamos as/os alunas/os, sendo que com as alunas éramos mais violentos, pois "cortávamos" o que elas tinham a dizer, o que não acontecia com os alunos, segundo relatavam. Embora discordamos dessa afirmativa naquele momento, primeiro porque após refletirmos percebemos que o "corte" era com todos, mas a exacerbação com o feminino se dava por haver mais mulheres e que estas falavam mais, embora neste mesmo processo reflexivo chegamos a conclusão de que era preciso evitar "cortar" as falas e que, embora ambos tentem escapar desse lugar de masculino como violento, nem sempre é possível. Isso pode ocorrer por diferentes motivos, seja por identificações, projeções externas, essencializações, socializações diárias, justificativas a ações, reiterações cotidianas, ou simplesmente por reagirmos em algumas situações.

Desta forma, ir para além do desconforto, não é fugir da responsabilidade como homem consciente dos privilégios sociais que possuímos, muito menos criar um discurso de vítima das condições sociais. É ir justamente ao encontro das palavras de Connell e Messerschmidt, (2013, p. 245) quando trazem que "talvez fosse possível que uma maneira de ser homem mais humana, menos opressiva, pudesse se tornar hegemônica como parte de um processo que levaria à abolição das hierarquias de gênero".

Enquanto essa possibilidade não se constrói, usamos das palavras de $\operatorname{Medrado}^{1}$ (2009, apud LAGO; RAMOS; BRAGAGNOLO, 2010, p. 40): "Defino-me como homem que defende os princípios feministas em prol de uma sociedade mais justa. Minha utopia (aquilo que me move) é por uma sociedade em que as diferentes formas de opressão geradas por uma ordem (ou dominação) masculina sejam eliminadas". E que esse homem proposto se conforte em um espaço de igualdades de condições e construções.

Compreendemos, portanto, que psicólogos homens podem utilizar os pressupostos feministas, especialmente no âmbito da Assistência Social, utilizando como ferramentas o saber localizado, o olhar para a diversidade, uma posição crítica a posição da norma e o que é excluído neste processo, o contínuo exercício de autorreflexão considerando os lugares de fala com suas limitações e as interseccionalidades, manter o olhar interpretativo e analítico para as questões do campo a partir do gênero, a desconstrução de categorias entendidas como fixas e estáveis, tensionando certezas, essencialismos, determinismos e, ainda, a atenção a políticas de igualdade de direitos para as mulheres e demais populações vulnerabilizadas.

Queremos chegar neste lugar de construção de um outro modo de atuação, mais crítica e com interesse na transformação social, ou seja, a construção de uma sociedade sem hierarquia de gêneros,

\footnotetext{
${ }^{1}$ MEDRADO, Benedito. A Lei Maria da Penha não é contra os homens, é a favor de uma sociedade sem violência: conquistas, lacunas e desafios em políticas públicas. In: Carmen Torquist; Clair Castilhos; Mara Coelho de Souza Lago; Teresa Kleba Lisboa. (Org.). Leituras de resistência: Corpo, Violência e Poder. Florianópolis: Universidade Federal de Santa Catarina, 2009, v. 1, p. 20-35.
} 
sem lugares marcados pelos privilégios masculinos, sem formas de violência baseadas no gênero. Significa afirmar que é possível ampliar a matriz de inteligibilidade e possibilitar que mais vivos sejam reconhecidos como vidas. Não é roubar o lugar de fala de mulheres, gays, lésbicas, bissexuais, transexuais, pessoas intersex, pessoas não-binárias, mais sim, falar de experiências, construir em conjunto, lugares democráticos e, portanto, igualitários.

\section{REFERÊNCIAS}

ANDRADE, Laura Freire de; ROMAGNOLI, Roberta Carvalho. O Psicólogo no CRAS: uma cartografia dos territórios subjetivos. Psicologia Ciência e Profissão, 30 (3), p. 604-619, 2010.

BEIRAS, Adriano. Experiencias internacionales y españolas de intervención con hombres para el cambio de las relaciones de género. In: Maria Freixanet Mateo (Ed.). Homes i gènere. Polítiques locals i la transformació de les masculinitats. Barcelona: ICPS, 2013. p.173-209.

. Relatório Mapeamento de Serviços de atenção grupal a homens autores de violência contra mulheres no contexto brasileiro. Rio de Janeiro: Instituto Noos, 2014. Disponível em: http://noos.org.br/portal/wp-content/uploads/2015/04/Relatorio-Mapeamento-SHAV_site.pdf. Acessado em 08/05/2018.

BEIRAS, Adriano; NUERNBERG, Adriano Henrique; ADRIÃO, Karla Galvão. Estudos de gênero na Psicologia Brasileira - perspectivas e atuações da terceira geração. Athenea Digital. 12 (3), p. 203-216, 2012. Disponível em: http://atheneadigital.net/article/view/Beiras. Acessado em $08 / 05 / 2018$.

BEIRAS, Adriano; BENVENUTTI, Mateus Pereira; TONELI, Maria Juracy. Os feminismos como ferramentas teóricas e epistemológicas no trabalho com homens autores de violência contra mulheres: reflexões e debates no contexto brasileiro e espanhol. In: Marlene Neves Strey; Sabrina Daiane Cúnico. (Org.). Teorias de gênero: feminismos e transgressão. 1 ed. Porto Alegre: EDIPUCRS, 2016, v. 1, p. 606-650.

BORGES, Lenise Santana. Feminismos, teoria queer e psicologia social crítica: (re)contando histórias... Psicologia \& Sociedade, 26(2), p. 280-289, 2014.

BRASIL. Constituição da República Federativa do Brasil. Brasília: Centro Gráfico do Senado Federal, 1988. de 1993.

. Presidência da República. Lei Orgânica da Assistência Social, n. 8.742, de 7 de setembro 
BRASIL. Ministério do Desenvolvimento Social e Combate a Fome. Política Nacional de Assistência Social PNAS/2004. Brasília: MDS, 2005.

. Ministério do Desenvolvimento Social e Combate a Fome. Orientações Técnicas: Centro de Referência de Assistência Social - CRAS. 1. ed. - Brasília: MDS, 2009.

. Ministério do Desenvolvimento Social e Combate a Fome. Orientações Técnicas: Centro de Referência Especializado de Assistência Social - CREAS. Brasília: Gráfica e Editora Brasil LTDA, 2011.

. Ministério do Desenvolvimento Social e Combate a Fome. Orientações Técnicas sobre o Serviço de Proteção e Atendimento Integral à Família - PAIF - volume 2: Trabalho Social com Famílias. Brasília: MDS, 2012

- Ministério do Desenvolvimento Social e Combate a Fome. Fundamentos ético-políticos e rumos teórico-metodológicos para fortalecer o Trabalho Social com Famílias na Política Nacional de Assistência Social. Brasilia: MDS, 2016.

BUTLER, Judith. Fundamentos Contingentes: O feminismo e a questão do "pós-modernismo". Cadernos Pagu, 11, p. 11-42. 1998. Disponível em:

http://www.ieg.ufsc.br/admin/downloads/artigos/Pagu/1998\%2811\%29/Butler.pdf. Acessado em $08 / 05 / 2018$.

. Problemas de Gênero: feminismo e subversão da identidade. Rio de Janeiro: Civilização Brasileira, 2003.

Quadros de guerra: quando a vida é passível de luto? Rio de Janeiro: Civilização Brasileira, 2015.

CENTRO DE REFERÊNCIA TÉCNICA EM PSICOLOGIA E POLÍTICAS PÚBLICAS (CREPOP). Conselho Federal de Psicologia. Referências técnicas para atuação de psicólogas (os) nos Centros de Referência Especializado de Assistência Social - CREAS. Brasília: CFP, 2013.

CHAGOYA, Melissa Fernández. Tendencias discursivas en el activismo de varones profeministas en México: algunas provocaciones a propósito del "cambio" en los hombres. Conexões Psi, v.2, n. 1, p.31-56, 2014. Disponível em http://apl.unisuam.edu.br/revistas/index.php/conexoespsi/article/view/324. Acessado em 08/05/2018. 
CONNELL, Robert; MESSERSCHMIDT, James. Masculinidade hegemônica: repensando o conceito. Revista Estudos Feministas, 21(1), p. 241-282, 2013.

CONSELHO FEDERAL DE PSICOLOGIA. Centro de Referência Técnica em Psicologia e Políticas Públicas - CREPOP. Referências Técnicas para atuação do/a psicólogo/a no

CRAS/SUAS. Brasília: CFP, 2007.

CONSELHO FEDERAL DE PSICOLOGIA. Centro de Referência Técnica em Psicologia e Políticas Públicas - CREPOP. Referência Técnica para Atuação de Psicólogas(os) em Programas de Medidas Socioeducativas em Meio Aberto. Brasília: CFP, 2012

CONSELHO FEDERAL DE PSICOLOGIA. Referências Técnicas sobre a Prática de Psicólogas (os) no Centro de Referência Especializado da Assistência Social - CREAS. Brasília: CFP, 2013.

FLOOD, Michael. Involving men in efforts to end violence against women. Men and Masculinities, 14 (3), p. 358-377, 2011.

GERGEN, Kenneth; GERGEN, Mary. Construcionismo social: um convite ao diálogo. Rio de Janeiro: Instituto Noos, 2010.

HARDING, Sandra. ¿Existe un método feminista?. 1998. Disponível em:

http://investiga.uned.ac.cr/cicde/images/documentos/metodo.pdf. Acessado em 08/05/2018.

HARAWAY, Donna. Saberes Localizados: a questão da ciência para o feminismo e o privilégio da perspectiva parcial. Cadernos Pagu, 5, 7-41. 1995. Disponível em:

http://www.ieg.ufsc.br/admin/downloads/artigos/31102009-083336haraway.pdf. Acessado em $08 / 05 / 2018$.

LAGO, Mara Coelho de Souza; RAMOS, Maria Eduarda; BRAGAGNOLO, Regina Ingrid. Enfrentamento da violência doméstica e familiar na legislação brasileira: Lei Maria da Penha. In: Toneli, Maria Juracy Filgueiras et al. (Orgs.). Atendimento a homens autores de violência contra as mulheres: experiências latino americanas. Florianópolis: UFSC/CHF/NUPPE, 2010. p. 28-48.

MOSCHETA, Murilo dos Santos. A pós-modernidade e o contexto para a emergência do discurso construcionista social. In: GUANAES-LORENZI, Carla. et. al. (Orgs.). Construcionismo social: discurso, prática e produção de conhecimento. Rio de Janeiro: Instituto Noos, 2014.

MORENO, Sara Yaneth Fernández. Varones y masculinidades en clave feminista: trascendiendo invisibilidades, ausencias y omisiones. Sexualidad, Salud y Sociedad (Rio de Janeiro), 22, p. 249277, 2016. Disponível em: https://dx.doi.org/10.1590/1984-6487.sess.2016.22.11.a 
NOGUEIRA, Maria Conceição. Contribuições do Construcionismo Social a uma nova Psicologia do Gênero. Cadernos de Pesquisa, 112, p. 137-153, 2001.

NOGUEIRA, Maria Conceição. A Teoria da Interseccionalidade nos estudos de género e sexualidades: condições de produção de "novas possibilidades" no projeto de uma psicologia feminista crítica. In.: Brizola, Ana Lídia C.; Zanella, Andrea V.; Gesser, Marivete. (orgs.) Práticas sociais, políticas públicas e direitos humanos. Florianópolis: Editora ABRAPSO, 2013. p. 227 248.

NOGUEIRA, Maria Conceição. Interseccionalidade e Psicologia Feminista. Salvador: Editora Devires, 2017

NÚÑEZ NORIEGA, Guillermo. Los "hombres" en los estudios de género de los "hombres": un reto desde los estudios queer. In: Ramírez Rodríguez, Juan; Uribe Vázquez, Griselda (Coords.), Masculinidades, el juego de género de los hombres en el que participan las mujeres. México: Plaza y Valdés, 2008. p. 43-57.

PRECIADO, Beatriz. Multidões queer: notas para uma política dos “anormais”. Estudos Feministas, 19(1), p. 11-20, 2011.

ROMAGNOLI, Roberta Carvalho. Relações macropolíticas e micropolíticas no cotidiano do CRAS. Psicologia \& Sociedade, 28 (1), p. 151-161, 2016.

SANTOS, Luane Neves. As psicólogas no SUAS: mobilizando recursos para uma atuação com compromisso social. Revista Psicologia, Diversidade e Saúde, 4(1), p. 40-49, 2015.

SCOTT, Joan Wallach. A invisibilidade da experiência. Projeto História, nº 16, fev., p. 297 325, 1998.

TONELI, Maria Juracy Filgueiras et al. (Org.). Atendimento a homens autores de violência contra mulheres: experiências latino-americanas. 1ed. Florianópolis: UFSC/CFH/NUPPE, 2010.

XIMENES, Verônica Morais; PAULA, Luana Rêgo Colares de; BARROS, João Paulo Pereira. Psicologia Comunitária e Política de Assistência Social: diálogos sobre atuações em comunidades. Psicologia Ciência e Profissão, 29 (4), p. 686-699, 2009.

YAZBEK, Maria Carmelita. et al. O Sistema Único de Assistência Social em São Paulo e Minas Gerais: desafios e perspectivas de uma realidade em movimento. In: Berenice Rojas Couto; YAZBEK, Maria Carmelita; Maria Ozanira da Silva e Silva; Raquel Raichelis. (Orgs.). O Sistema Único de Assistência Social no Brasil: uma realidade em movimento. $4^{\mathrm{a}}$ ed. São Paulo: Cortez Editora, 2014. p. 138-204. 
Recebido em: 10-5-2018

Histórico Revisado em: 2-7-2018

Aceito em: 5-9-2018 